\title{
'It is not in my world': an exploration of attitudes and influences associated with cystic fibrosis carrier screening
}

\author{
Belinda J McClaren ${ }^{1,4}$, Martin B Delatycki ${ }^{2}$, Veronica Collins ${ }^{3}$, Sylvia A Metcalfe ${ }^{1,4}$ and \\ MaryAnne Aitken*,1,4
}

\author{
${ }^{1}$ Genetics Education and Health Research, Murdoch Childrens Research Institute, Royal Children's Hospital, Parkville, \\ Victoria, Australia; ${ }^{2}$ Murdoch Childrens Research Institute, Bruce Lefroy Centre for Genetic Health Research, Royal \\ Children's Hospital, Parkville, Victoria, Australia; ${ }^{3}$ Public Health Genetics, Murdoch Childrens Research Institute, \\ Royal Children's Hospital, Parkville, Victoria, Australia; ${ }^{4}$ Department of Paediatrics, The University of Melbourne, \\ Parkville, Victoria, Australia
}

Carrier screening for cystic fibrosis has been recommended for pregnant women and their partners, individuals and couples prior to conception, and for people with a family history. Many pilot programmes offering cystic fibrosis carrier screening, most commonly in the prenatal setting, have shown that uptake and acceptability are high. This article explores perspectives of the Victorian community regarding carrier screening for cystic fibrosis prior to offering screening. In particular whether or not such carrier screening should be offered, the best time for offering carrier screening, the information required for making a decision about carrier screening, and how this information can best be provided. A qualitative approach was taken to enable exploration of the views of stakeholders. Four focus groups and 32 interviews were conducted with a total of 68 participants. Participants were in agreement that cystic fibrosis carrier screening should be made available to everyone. However, potential consumers viewed cystic fibrosis carrier screening as 'not in my world' and were unlikely to request such screening unless it was offered by a health professional, or they had a family history. The best time for carrier screening was seen to be an individual preference and an information brochure was perceived to be useful when considering carrier screening. Lack of knowledge around the irrelevance of family history is a barrier to cystic fibrosis carrier screening. This study highlights the importance of community consultation, with stakeholders, prior to implementation of carrier screening programmes.

European Journal of Human Genetics (2008) 16, 435-444; doi:10.1038/sj.ejhg.5201965; published online 5 December 2007

Keywords: cystic fibrosis; attitudes; carrier screening; population screening; genetic screening

\footnotetext{
*Correspondence: Dr MA Aitken, Genetics Education and Health Research, Murdoch Childrens Research Institute, 10th Floor, Royal Children's Hospital, Flemington Road, Parkville, Victoria 3052, Australia. Tel: + 6138341 6209; Fax: + 6138341 6212;

E-mail: maryanne.aitken@mcri.edu.au

Received 3 July 2007; revised 12 October 2007; accepted 30 October 2007; published online 5 December 2007
}

\section{Introduction}

Affecting about 1 in 2500 Caucasians and having a carrier frequency of 1 in 25, cystic fibrosis (CF) is the most common, severe, recessive, genetic condition in children in Australia. Newborn screening for CF has been routine since 1989 in the State of Victoria, Australia. ${ }^{1}$ In addition to the primary outcome of identifying infants with $\mathrm{CF}$, newborn screening may identify some carriers of CF. Furthermore, some relatives of infants identified as having 
CF may undergo cascade testing to learn their carrier status. However, it has been estimated that over $90 \%$ of carriers are unaware of their carrier status. ${ }^{2}$ CF carrier screening programmes have been piloted as a way of identifying these carriers. ${ }^{3-7}$ Prior to implementation of screening programmes, a process of inclusive consultation with stakeholders is integral for community support. ${ }^{8,9}$ This paper describes consultation with stakeholders prior to the availability of a government funded population $\mathrm{CF}$ carrier screening programme, and is an initial step in understanding community attitudes to the concept of CF carrier screening in the Australian context. In January 2006, a user pays pilot CF carrier screening programme, available in a few metropolitan private obstetric clinics, was launched in Victoria, Australia.

Published guidelines about carrier screening for CF identify key stakeholders as being pregnant couples; couples and individuals prior to conception; people with a family history of CF; and health professionals such as general practitioners likely to be involved in offering carrier screening. ${ }^{10}$ In line with these recommendations, community consultation regarding implementation and uptake of CF carrier screening programmes has been described in the literature, ${ }^{1-15}$ for example, in the Netherlands, attitudes and intentions of potential consumers of preconception CF carrier screening programmes have been investigated. ${ }^{16-20}$ Community consultation has occurred both with and without the offer of carrier screening, and most commonly with only one stakeholder group at a time. Drawing on these published findings, we report our study that involves consultation with stakeholders of CF carrier screening, prior to implementation. No other Australian study to date has included participants that represent all the recommended stakeholder groups prior to offering carrier screening. Using focus groups and interviews, this study has explored whether or not $\mathrm{CF}$ carrier screening should be offered in the Australian setting, the best time for offering carrier screening, the information required for making a decision about carrier screening, and how this information can best be provided.

\section{Materials and methods \\ Ethics}

This study was approved by the Human Research Ethics Committee of the Department of Human Services, State Government of Victoria, Australia (HREC 15/05).

\section{Methodology}

Qualitative data collection methods were chosen to enable an exploration of attitudes and information needs of the Australian community for carrier screening for CF. Openended questions, informed by the literature, were used in the semi-structured focus group and interview schedule. This methodology provided the opportunity for partici- pants to have the freedom to take the discussion in any direction while keeping some focus on the topics under investigation.

\section{Participants}

The groups included in this study were specified by carrier screening guidelines: pregnant women and their partners; individuals and couples prior to conception; people with a family history of CF. Also included were potential providers who may be involved in offering carrier screening tests, such as general practitioners and obstetricians, and other health professionals involved in the care of CF patients and their families. Participants were required to be over the age of 18 and English speaking. Pregnant women and their partners were only included if the pregnancy was no more than 12 weeks gestation at the time of the interview or focus group. This was to allow an appropriate time frame if carrier screening was initiated as a result of increased awareness for the carrier screening test and subsequent prenatal diagnosis requested. A summary of all participants and recruitment methods may be found in Table 1.

\section{Recruitment of participants \\ Potential providers and other health professionals Health} professionals that may be involved in offering carrier screening for CF include general practitioners and obstetricians. In this study, Victorian general practitioners and obstetricians were selected from telephone directory (White Pages $^{\mathrm{TM}}$ ) listings of practices in the local metropolitan Melbourne area, and sent a letter of invitation to participate in an evening focus group at the Royal Children's Hospital, Melbourne. In addition, an email bulletin was distributed to staff at the Royal Children's Hospital outlining the study and inviting participation in a focus group. Victorian health professionals involved in $\mathrm{CF}$ care attending the sixth Australian and New Zealand Cystic Fibrosis Conference 2005, in Adelaide, Australia were invited to participate in a lunchtime focus group held at the conference.

Pregnant couples Pregnant women and their partners were recruited face-to-face in the waiting rooms of obstetric and prenatal clinics in metropolitan Melbourne, Victoria. Interested people provided their contact details and were telephoned within 1 week and allocated to a focus group or were interviewed, either as a couple or individually.

Individuals and couples prior to conception University students who were not pregnant and did not have children were recruited using posters advertising a lunchtime focus group at The University of Melbourne, Australia. Students contacted the researcher to indicate their intention to attend the focus group. The focus group was limited to 10 participants. Couples prior to conception were recruited using snowball sampling of contacts of the researchers and 
Table 1 Characteristics of participants and data collection methods

\begin{tabular}{|c|c|c|c|c|c|c|}
\hline Source & $\begin{array}{c}\text { Total } \\
\text { participants }\end{array}$ & Description & $\begin{array}{l}\text { Focus } \\
\text { group }\end{array}$ & $\begin{array}{c}\text { Group } \\
\text { interview }\end{array}$ & $\begin{array}{c}\text { One-to-one } \\
\text { interview }\end{array}$ & Comments on recruitment \\
\hline $\begin{array}{l}\text { Victorian } \\
\text { health } \\
\text { professionals }\end{array}$ & 12 & $\begin{array}{l}\text { General practitioners } \\
(n=2), \text { obstetrician } \\
(n=2), \text { midwives }(n=2), \\
\text { physiotherapists }(n=4), \\
\text { social worker }(n=1), \\
\text { genetic counsellor }(n=1)\end{array}$ & 2 & & & $\begin{array}{l}\text { A focus group of potential providers (general practitioners, } \\
\text { obstetricians, and midwives) discussed barriers and benefits to offering } \\
\text { CF carrier screening. } \\
\text { Other health professionals who work in the field of CF care were } \\
\text { included, drawing on their extensive experience of CF and the CF } \\
\text { community, to examine additional potential issues around offering CF } \\
\text { carrier screening }\end{array}$ \\
\hline $\begin{array}{l}\text { Pregnant } \\
\text { couples }\end{array}$ & 15 & $\begin{array}{l}\text { Pregnant women } \\
(n=11) \\
\text { Partners of pregnant } \\
\text { Women }(n=4)\end{array}$ & & 2 & 10 & $\begin{array}{l}\text { Initial recruitment yielded participants for two group interviews; one } \\
\text { with three pregnant women and one with two pregnant women; no } \\
\text { partners of these women participated. During recruitment one-to-one } \\
\text { interviews were said to be preferable. A further six women and four of } \\
\text { their partners participated in one-to-one interviews. }\end{array}$ \\
\hline $\begin{array}{l}\text { Individuals } \\
\text { and couples } \\
\text { prior to } \\
\text { conception }\end{array}$ & 19 & $\begin{array}{l}\text { University students from } \\
\text { faculties of Arts, } \\
\text { Medicine, Engineering } \\
\text { and Science }(n=10) \\
\text { People planning a } \\
\text { pregnancy within a few } \\
\text { years }(n=9)\end{array}$ & 2 & & & $\begin{array}{l}\text { Sampling from the preconception population was achieved by inviting } \\
\text { university students to a lunchtime focus group; and holding an } \\
\text { evening focus group with couples who are planning to have children in } \\
\text { the near future. There were four couples in this second group and one } \\
\text { male whose partner was unable to attend due to illness. }\end{array}$ \\
\hline $\begin{array}{l}\text { People with a } \\
\text { family history } \\
\text { of CF/adults } \\
\text { with CF }\end{array}$ & 22 & $\begin{array}{l}\text { Grandparents }(n=5) \\
\text { parents }(n=11) \text {, siblings } \\
(n=2) \text {, aunt }(n=1) \\
\text { adults with } C F(n=3)\end{array}$ & & 4 & 14 & $\begin{array}{l}\text { Four grandparents and four parents wished to be interviewed as } \\
\text { couples. All other interviews were one-to-one for reasons including } \\
\text { maintaining confidentiality of participants among the Victorian CF } \\
\text { community, potential for cross-infection of adults with CF and } \\
\text { convenience for participants. }\end{array}$ \\
\hline Total & 68 & & 4 & 6 & 24 & $\begin{array}{l}\text { Focus groups were chosen as the qualitative data collection method to } \\
\text { allow interaction and discussion among participants. Recruitment for } \\
\text { focus groups proved to be a barrier to participation of pregnant } \\
\text { women and their partners and interviews (group and one-to-one) were } \\
\text { held instead. For people with a family history of CF it was felt that focus } \\
\text { groups may restrict participants' willingness to share their opinions } \\
\text { freely so recruitment was for interviews only. }\end{array}$ \\
\hline
\end{tabular}

Participant numbers (n) are in brackets. 
were sent a letter of invitation to attend an evening focus group. $^{21}$

People with a family history of $C F$ Participants with a family history of CF were invited to be interviewed via advertisements mailed to Cystic Fibrosis Victoria members.

\section{Focus group and interview procedure}

All focus groups and interviews were conducted over a 12month period beginning in May 2005. Three and two group interviews focus groups were facilitated by MA with the remaining focus group (Victorian health professionals involved in CF care) and all other interviews facilitated by BM. Participants were not given any specific information about CF or carrier screening prior to participation. However, information including a description of the clinical aspects of $\mathrm{CF}$, the inheritance pattern of $\mathrm{CF}$ and the process of having CF carrier screening was provided as needed during the focus group or interview. Interviews and focus groups discussed the following: factors that contribute to health; attitudes to carrier screening; attitudes to carrier screening for CF specifically; best time to be offered carrier screening; and information required to make a decision about having carrier screening. The focus groups with health professionals explored attitudes specifically towards being involved in offering carrier screening, patient needs, and the information resources that may assist this process. Interviews and focus groups were digitally recorded and transcribed verbatim, with each participant assigned a pseudonym.

\section{Analysis}

Using NVivo 7 (QSR International Pty Ltd, Melbourne, Australia) for data management, transcripts of the focus groups and interviews were coded for emergent themes using a constant comparison approach. ${ }^{22}$ Data were not analysed for differences between focus group and interview methodology. Analysis of transcripts was performed independently by researchers BM and MA and then compared for coding reliability through a process of discussion and deliberation of themes and connections between themes. $^{21}$

\section{Results}

Recruitment methods yielded 68 participants with data collected in 4 focus groups and 32 interviews (Table 1). The results presented in this paper outline major themes that emerged from the focus group and interview discussions.

Potential consumers and people with a family history: attitudes and influencing factors

Pregnant couples, individuals and couples prior to conception, and people with a family history of CF were asked to discuss their attitudes towards carrier screening. Participants were supportive of CF carrier screening being made available to those who wish to have it.

"I think it is important to have those facilities available to people."

Heidi (pregnant woman)

"I actually don't think there is really a right or wrong answer, I think it is nice to have the option...think it is a good thing for it to be offered, not compulsory...I don't think there is a right or a wrong but I think from where I sit,

to have that (CF carrier screening) offered is a good thing." Gemma (mother of adult with CF)

Some participants had reservations about widespread offering of CF carrier screening to the community.

"I think I'd want to know but, yeah personally I'd want to know. I don't know if it is a good thing generally for people to know."

Thomas (university student)

In discussion of attitudes to carrier screening and being offered carrier screening personally, participants identified factors they would consider before either seeking out screening or accepting the offer of screening. Participants identified three key factors that would influence their personal decision regarding carrier screening for CF.

\section{(1) Prior experience}

Attitudes were influenced by participants' prior experiences and what they are familiar with.

"I must have heard of it but it is never something I think about, 'I should have testing', because it is not in my world I suppose, or my family."

\section{Kate (pregnant woman)}

\section{Family history of a genetic condition}

Prior experience in terms of a family history of a genetic condition was said to be a factor that would influence participants' decisions about having CF carrier screening. For some participants their decision would be made in the light of a known family history of a condition other than CF.

"He (my partner) probably would be happy about it (having CF carrier screening) because on his side of the family he does have a niece who has... lots of brain tumours...was very traumatic for them when she was little."

Rebecca (pregnant woman)

Family history of CF

Participants with a family history of CF also recognised the importance of family history as a motivator for 
screening, yet many of their family members were not screened.

"I have got a brother who has had several children...I think he's got blinkers on because his attitude is that 'It won't happen to me'."

Jade (mother of adolescent with CF)

\section{(2) Life stage when offered carrier screening}

Advanced maternal age was said by participants to be a reason to consider CF carrier screening.

"I don't know what you would define as an old mum but I am 31 so I guess I would be thinking about, if I was going to have kids soon I would be thinking about that."

Casey (couple)

"With women being older as well you just hear so many stats about, 'You're prone to this, you're prone to that' because you might be (aged) 30-something not 20something so maybe you would (have CF carrier screening) because you are concerned."

Kara (pregnant woman)

CF carrier screening was seen to be most important for people who want to have children; if people were not of childbearing age, screening was perceived to be less important.

"They (family members) are aware that these tests are out there. None of them have...got to a point in their life where they need to really consider it...It is something that only really becomes relevant I suppose when you are looking to have kids."

Cameron (sibling of adult with CF)

"I wouldn't actually want screening for myself right now; only if I were to have children I would want to be screened."

Catherine (university student)

\section{(3) Recommendation of a health professional}

Participants without a family history of CF perceived a low risk of being a carrier yet discussed being willing to have screening if it were recommended by their health professional.

"I guess if the doctor encouraged me to have (carrier screening) I probably would think about having it."

Casey (couple)

"I would have, if someone had suggested it to me with good reason, as I said I don't know much about it, but if someone said to me 'you fall into a certain category or we think'... if someone had said that to me, yeah."

Deborah (pregnant woman)

Routine screening

For many participants, knowing that screening was routine was important in influencing their decision. This was illustrated by participants discussing Down syndrome screening. Participants described their experience of accepting this screening because it was routine and easily available.

"Look the decision to have a test like that (carrier screening for CF), I'd need to know, is it common practice?... See Downs (syndrome screening)... is now such common practice that it is more unusual that those that haven't had it done than those that have, especially as you get older. So what would influence me? Much like that, it is just the done thing... if it is part of what one does."

Murray (partner of pregnant woman)

Potential providers' and other health professionals: attitudes and influencing factors

Potential providers and other health professionals had two important perspectives on the implementation of carrier screening for CF; firstly their personal attitude towards offering carrier screening to patients, and secondly drawing on their experience to discuss potential impact and acceptability of a screening programme for their patients. Participants identified that as health professionals they are likely to be providers of CF carrier screening and were positive about this role.

"I see it as part of my job; I am supposed to give people all of the options."

Mike (general practitioner)

Participants in this study were aware of the influencing effect health professionals' recommendations have on people's decision about screening.

"I think we underestimate the power of the balance between health professionals and consumers because they still tend to look at the doctor or health care professional with knowledge base of information and they look up to (them)."

Dianna (physiotherapist)

"If someone comes to me and says 'I'm thinking about having a baby soon', then I would, yes I would sort of talk about genetics, serum screening, ultrasound, and say 'These tests are available'. Interestingly enough I think that once you raise it with them and once you say 'Most people these days seem to have it', although they have a perfect right to say ' $\mathrm{No}$ ' there are very few, sort of say after that they won't have it, whereas my guess is that if we didn't raise it with the women, they wouldn't have it."

Tina (obstetrician)

Given that health professionals are likely to be providers, and the influencing nature of their opinion, participants' attitudes were positive towards theoretical screening but 
more reserved when considering routinely offering screening.

"The question is would you, we, routinely screen every women or every couple who came through the door? I think I wouldn't, no."

Shane (obstetrician)

Participants' further discussed their reservations at offering CF carrier screening routinely.

(1) Psychosocial impact for patients: stigma and stress on relationships

Health professionals discussed psychosocial outcomes for their patients as a result of CF carrier screening. The potential for carriers to be seen as 'undesirable' in the community influenced the extent to which these health professionals felt comfortable offering CF carrier screening to their patients.

"Does that mean they become undesirable or that, even worse, that group that are carriers, because the non-carriers aren't interested, start intermarrying and therefore increase their rate of potential (for having a child with CF)?"

Mike (general practitioner)

A further perceived negative outcome of CF carrier screening that health professionals foresaw was the potential for stress to their patients' existing relationships.

"I think the other big concern is relationships as well. Is testing going to have effects on people found to be carriers and their partner is not? There could be ramifications on that where it could cause problems."

Justin (physiotherapist)

\section{(2) Time constraints in practice}

Health professionals in this study, perceived offering carrier screening as a burden given the time constraints already present in consultations.

"The reality is that you can't, in a normal consultation you can't adjust it to what they have come for, they might come for infertility, just to cover all that is virtually impossible let alone to say 'and by the way we have got this new test we can do'. It is not realistic."

Shane (obstetrician)

\section{Most appropriate time for carrier screening to be offered}

All participants, expressed opinions regarding the various situations or life stages in which CF carrier screening may be offered. Discussion was both in response to questions asked by the researcher and participant initiated. Most participants were reluctant to definitively state a preference for one 'best time' for CF carrier screening to be offered. Instead participants felt that different people would be ready at different times. They supported CF carrier screening being available in a variety of settings, providing an opportunity for a personal choice to be made when they felt ready to decide about carrier screening.

\section{(1) Carrier screening during pregnancy}

Carrier screening during pregnancy was often said to be 'too late' (Rochelle, parent of adolescent with CF); however, participants felt that this was the most practical time to offer carrier screening.

"I think practically if you are trying to introduce something like this you have to go to pregnant women and try and introduce it in some forum where pregnant women congregate, like obstetricians, because that is the only time you will get the attention of the right people, and probably the motivation in them to consider it."

Heidi (pregnant woman)

"I think the theory is that, it would probably be best in an obstetrics setting where pregnancy is on the mind, but the reality is that in obstetrics most people would arrive there already pregnant."

Ally (genetic counsellor)

Carrier screening during pregnancy was thought to provide information that may help to prepare for the birth of a child with CF. The period of time in which a child is diagnosed with CF was described by parents of children with CF to be very distressing and confusing as they had been unaware of their carrier status.

"It would prepare you for when the baby is born if you knew that there was a problem, it might be easier to sort of deal with it while you are pregnant instead of having the baby and finding out something was wrong with the baby unless you sort of know."

Melanie (pregnant woman)

"It is not ideal probably but if it can't be offered before pregnancy, then during pregnancy I think. Yeah it is a tricky one. Because it might just be finding out about what the condition is and being prepared for the fact that the baby may well have CF and what that means."

Leanne (parent of toddler with CF)

(2) Screening prior to pregnancy: preconception or high school

It is uncommon for CF carrier screening to be offered or requested prior to pregnancy. Participants felt this may be due to people not thinking about having children.

"You aren't really thinking about having kids, well I wasn't, I was planning my career."

Camilla (pregnant woman)

"I think when people are having babies, yes they are reasonably (interested)... but perhaps the rest of the population, they don't worry about it too much."

Tina (obstetrician) 
Participants supported CF carrier screening prior to pregnancy identifying that at this time the maximum reproductive choices are available to a carrier couple. It was seen to be beneficial to know carrier status prior to conception to be able to make reproductive decisions without the pressure of considering termination of pregnancy.

"I suppose people would want to have tests done so it gives them a bit of certainty and also a choice whether they need to choose to have children if they find out they have something, or there is a risk so you have some certainty about what you are carrying, so you know the facts I suppose and you can make a choice."

Richard (couple)

Also discussed was the possibility of CF carrier screening being offered to high school students. Participants who supported this approach felt that this would enable the population to be reached en masse.

"If you don't catch a group of people altogether, maybe it mightn't happen, do you know what I mean, it is like if they are already in a group being at a secondary school, so then they would discuss that with their parents and then the parents may think that is a good thing, I'm not sure. I think if you don't get people in a group it is all sort of like 'I don't even have to think about it'. I think it is probably a good idea."

Eden (grandparent of child with CF)

In contrast to this, some participants felt young people would not be mature enough, may experience stigma or peer pressure and, the information may not be seen as relevant for many years.

"It seems a little bit early to me, but then again it might be a logical way of getting the kids. Once they are all at work, how do you, like when they turn 21 you say 'hey you've got this offer'?...It might be a good way of eliminating the condition, getting it early, educating people early and getting all the carriers...Yeah, I think it would be generally good..."

Mark and Danielle (parents of infant with CF)

\section{Recommendations for information resources (1) Content}

Participants' responses regarding what information they would require to assist them make a decision about carrier screening (or assist with offering screening) can be found in Box 1. This information was discussed in response to direct questions about information requirements but also represents questions that the participants asked the researchers during the focus group or interview.
Box 1 Participants' recommendations for content of information resources provided with an offer of carrier screening for $\mathrm{CF}$

What is CF?
Who is at risk?
What is the test procedure?
How sensitive is the test?
What do the results mean? Is it diagnostic or a risk estimate?
What happens next?
How confidential are the results? Can insurance be affected?
How much does the test cost?
Is the test common/routine?
Does maternal age affect risk?

Facts about $C F$ and the carrier screening procedure

"I think it needs to be straight down the line, facts. Talk about life expectancy, quality of life, the number of deaths per year, the ages of the people who die...the restrictions on family life, the effect on siblings, the effect on parents, grandparents, as well as obviously the effect of living with a life threatening condition."

Alissa (parent of adult with CF)

"It needs to have the hard cold facts as well in there because you want to be able to take on board, apart from the jokes and all that, you need to have the serious side." Kara (pregnant woman)

Prenatal diagnosis after carrier screening

Participants wanted information about prenatal diagnostic tests that may need to be considered following carrier screening. They felt hesitant about having prenatal testing especially when their perceived risk of disease is much lower than their perceived risk of miscarriage from diagnostic tests.

"What is the risk of miscarriage? All that sort of stuff. Is it just a swab of the inside of your cheek or is it a needle into the womb?"

Danielle (parent of infant with CF)

\section{(2) Use of resource}

Participants felt that a brochure containing the information in Box 1 would be useful as they could take it home and refer to it when considering CF carrier screening.

"I have a little stack of them (brochures) at home in a folder and occasionally I will go back and look through them as I start to think about things and as the pregnancy goes ahead and one becomes a bit more relevant."

Rebecca (pregnant woman)

\section{Discussion}

Using focus groups and interviews, this qualitative study has engaged stakeholders of a potential CF carrier 
screening programme in the State of Victoria, Australia. ${ }^{10}$ Together with previously reported studies investigating various aspects of carrier screening for CF, this study provides valuable information that may be considered prior to implementing CF carrier screening programmes.

Carrier screening for CF was supported by most participants, with agreement that CF carrier screening should be available to everyone. Participants described positive attitudes towards being offered CF carrier screening, yet identified that they would be unlikely to accept or request such an offer without prior knowledge of a family history of CF. Accepting the offer of CF carrier screening was influenced by the life stage at which a person is offered it, but the strongest motivator, in the absence of a family history, was said to be the recommendation of a health professional. Participants recognised that a health professional who presents carrier screening as routine will influence a decision to accept the offer of carrier screening. Health professionals in this study identified that they would be likely to have this role, and as such were willing to offer screening to some of their patients. It was clear in this study that routinely offering CF carrier screening is not well supported by health professionals because of their perceptions of the potential for psychosocial harms to patients, and the increased burden such an offer would place on already time-poor consultations. Provision of information resources with the offer of carrier screening was seen to be imperative and participants described the anticipated use of such information in assisting decision making about CF carrier screening. The best time to offer screening was said to be variable for different people. As such participants felt offering CF carrier screening at several life stages would allow people to make the decision when they were ready.

Positive attitudes towards carrier screening for CF demonstrated by participants in this exploration are in agreement with other published studies. ${ }^{3,5,18,19,23-28}$ It was concluded by Poppelaars et al ${ }^{18,20}$ that barriers to screening reported in their studies may be specific to the context of The Netherlands; however, they suggest these barriers may also be universal. This Australian perspective concurs with their proposal and suggests that there are community attitudes, influences and barriers that are common among differing health systems internationally.

Participants in this study demonstrated that their attitudes towards carrier screening for CF were influenced by their preconceived ideas, in particular with reference to their understanding of the role of family history and maternal age. Participants described their perception that a family history of CF would be a strong motivator for considering CF carrier screening. In fact, in Australia the population CF carrier frequency is one in 25 and it has been estimated elsewhere that over $90 \%$ carriers are unaware of their status. ${ }^{2}$ This demonstrates that participants were unaware of the likelihood of being a CF carrier
(1 in 25) and misunderstood the inheritance patterns of autosomal recessive conditions like CF, where a child with CF may be born into a family in which no previous members were affected. In addition to family history motivating participants to accept the offer of carrier screening, participants felt that CF carrier screening would be more relevant if maternal age was advanced. CF carrier risk does not increase with advanced maternal or paternal age. It is possible that this misunderstanding demonstrated by participants reflects community familiarity with Down syndrome and advanced maternal age. This example illustrates how participants have transferred the message about advanced maternal age and are applying an indication of increased risk of Down syndrome to an increased risk of being a carrier for CF. These above examples of participant attitudes being derived from misinformation may provide insight into the lack of interest in carrier screening reported previously. ${ }^{12}$

For participants in this study, an attitude that CF and carrier screening 'is not in my world' was the primary reason that they probably would not accept the offer of carrier screening despite supporting the availability of $\mathrm{CF}$ carrier screening. This attitude suggests that CF carrier screening programmes will require a strategy to bring $\mathrm{CF}$ and carrier screening into people's 'world'. This may be possible with community education initiatives that continue to focus on, prior to and in parallel with programme implementation, community consultation regarding the information provided with the offer of screening and, additionally initiatives that aim to increase public awareness and understanding of genetics and carrier screening. ${ }^{6,26}$ It is well recognised that information resources have a role in aiding decision making regarding carrier screening. ${ }^{10,29}$ In 1998, Loeben et al ${ }^{29}$ evaluated 28 written resources, concluding that the way information is presented is also important. In the present study, participants were asked about the content and format of information that they would like to assist them to make a decision regarding CF carrier screening (Box 1). This study did not measure informed decision making, rather the aim was to explore stated factors that influenced attitudes. However, we recognise that informed decision making is an integral component of carrier screening. Participants in this study anticipated accepting CF carrier screening if it is part of what one does' (Murray, partner of pregnant woman), highlighting a difficulty with ensuring decisions are informed if the test is perceived to be routine.

While ongoing consultation with stakeholders is recommended to ensure that information needs are met so good knowledge can be achieved, enabling informed decisions to be made, this present study indicates that there is a need for awareness of relevant issues earlier than the acute time surrounding the offer of carrier screening. ${ }^{30}$ An attitude of 'it is not in my world' limits the usefulness of resources provided with the offer of screening. People have to 
consider genetics and carrier screening in their 'world' before they will begin to make use of information resources pertaining to the offer of carrier screening. Consequently, such resources will not correct the misunderstandings that have contributed to the attitude 'it is not in my world' displayed by participants in this study.

Public education and awareness campaigns may provide opportunities for such misunderstandings to be clarified. These may include interventions in structured educational settings including high school or using popular culture such as television programmes. Research would be needed to evaluate the impact of such approaches regarding effectiveness in dispelling misunderstandings such as those demonstrated by participants in this study. In addition to community focused strategies, a more individualised approach may be to equip health professionals to provide this education. In this study, health professionals saw offering screening as part of their role yet their capacity was diminished because of psychosocial concerns and time constraints. Gordon et al describe stigma resulting from identification of carrier status by carriers in their study to be 'low level or insignificant compared to knowing their carrier status' ${ }^{6}$ Examples can also be found in the literature where carriers were identified in screening programmes such as the Montreal experience of Tay-Sachs disease screening do not report stigma. ${ }^{31}$ Further research and dissemination of findings to health professionals may alleviate these concerns, making the prospect of offering carrier screening more acceptable to health professionals. ${ }^{26}$ The time required to offer and discuss CF carrier screening with patients may continue to be a barrier for some health professionals; however, addressing their concerns and providing well-researched resources may reduce the impact of the perceived burden of time constraints.

The study presented in this paper is not intended to be generalised, rather it is a snapshot of participants' attitudes to carrier screening. A wide focus was chosen to include all stakeholder groups rather than one at a time. This is a strength of the study and also a limitation as some stakeholder groups were represented by more participants than others. Self-selection as a result of purposive sampling introduces bias into the data where those who participate may have strong views around carrier screening for CF. These strong views may not represent the views of the wider community. This bias necessitates caution with reporting results; however, future quantitative investigation of themes that emerged from this study may reduce the impact of this bias. A quantitative study in a representative sample of the Australian population is planned.

Community consultation prior to the implementation of CF carrier screening programmes is necessary and achievable. Stakeholders should be provided an opportunity to explore their attitudes to such programmes and in doing so barriers and facilitators may be identified. This study has demonstrated that attitudes and the factors that influence attitudes to CF carrier screening can be based on misinformation. Failure to address this misinformation will limit the scope of a carrier screening programme. Asking time-poor health professionals who have concerns about the psychosocial impact for their patients to offer carrier screening to people who view it as 'it is not in my world' is unlikely to result in CF carrier screening being offered to those for whom information about carrier status is most relevant; the $90 \%$ of carriers unaware of their status. Ongoing public and health professional education is required. Through education and the provision of resources to aid both the offer and the decision regarding $\mathrm{CF}$ carrier screening, concerns of stakeholders that were based on misinformation can be addressed.

\section{Acknowledgements}

We thank all the participants in this study for their generosity of time and willingness to share their experiences. In addition, we thank the individuals and organisations that assisted with recruitment, in particular Cystic Fibrosis Victoria, and Dr Andrew Ngu, Women's Imaging Centre, Freemasons Private Hospital. We would like to thank Dr Sharon Lewis, Public Health Genetics, Murdoch Childrens Research Institute for valuable comments on this manuscript. There are no competing interests.

\section{References}

1 Massie RJ, Olsen M, Glazner J, Robertson CF, Francis I: Newborn screening for cystic fibrosis in Victoria: 10 years' experience (1989-1998). Med J Aust 2000; 172: 584-587.

2 Williamson R: Universal community carrier screening for cystic fibrosis? Nat Genet 1993; 3: 195-201.

3 Wake SA, Rogers CJ, Colley PW, Hieatt EA, Jenner CF, Turner GM: Cystic fibrosis carrier screening in two New South Wales country towns. Med J Aust 1996; 164: 471-474.

4 Loader S, Caldwell P, Kozyra A et al: Cystic fibrosis carrier population screening in the primary care setting. Am J Hum Genet 1996; 59: 234-247.

5 Henneman L, Bramsen I, van Kempen L et al: Offering preconceptional cystic fibrosis carrier couple screening in the absence of established preconceptional care services. Community Genet 2003; 6: 5-13.

6 Gordon C, Walpole I, Zubrick SR, Bower C: Population screening for cystic fibrosis: knowledge and emotional consequences 18 months later. Am J Med Genet 2003; 120A: 199-208.

7 Fang CY, Dunkel-Schetter C, Tatsugawa ZH et al: Attitudes toward genetic carrier screening for cystic fibrosis among pregnant women: the role of health beliefs and avoidant coping style. Womens Health 1997; 3: 31-51.

8 Aitken MA, Metcalfe SA: The social imperative for community genetic screening: an Australian perspective; in: Betta M (ed): The Moral, Social, and Commercial Imperatives of Genetic Testing and Screening. Netherlands: Springer, 2006, pp 165-184.

9 Godard B, ten Kate L, Evers-Kiebooms G, Ayme S: Population genetic screening programmes: principles, techniques, practices, and policies. Eur J Hum Genet 2003; 11 (Suppl 2): S49-S87.

10 National Institutes of Health: Consensus Development Conference Statement on Genetic Testing for Cystic Fibrosis. Arch Intern Med 1999; 159: 1529-1539. 
11 Boulton M, Cummings C, Williamson R: The views of general practitioners on community carrier screening for cystic fibrosis. Br J Gen Pract 1996; 46: 299-301.

12 Clayton EW, Hannig VL, Pfotenhauer JP, Parker RA, Campbell III PW, Phillips III JA: Lack of interest by nonpregnant couples in population-based cystic fibrosis carrier screening. Am J Hum Genet 1996; 58: 617-627.

13 Watson EK, Williamson R, Chapple J: Attitudes to carrier screening for cystic fibrosis: a survey of health care professionals, relatives of sufferers and other members of the public. Br J Gen Pract 1991; 41: 237-240.

14 Honnor M, Zubrick SR, Walpole I, Bower C, Goldblatt J: Population screening for cystic fibrosis in Western Australia: community response. Am J Med Genet 2000; 93: 198-204.

15 Payne Y, Williams M, Cheadle J et al: Carrier screening for cystic fibrosis in primary care: evaluation of a project in South Wales. The South Wales Cystic Fibrosis Carrier Screening Research Team. Clin Genet 1997; 51: 153-163.

16 Henneman L, Bramsen I, van der Ploeg HM et al: Participation in preconceptional carrier couple screening: characteristics, attitudes, and knowledge of both partners. J Med Genet 2001; 38: $695-703$.

17 Henneman L, Bramsen I, Van Os TA et al: Attitudes towards reproductive issues and carrier testing among adult patients and parents of children with cystic fibrosis (CF). Prenat Diagn 2001; 21: 1-9.

18 Poppelaars FA, Henneman L, Ader HJ et al: How should preconceptional cystic fibrosis carrier screening be provided? Opinions of potential providers and the target population. Community Genet 2003; 6: 157-165.

19 Poppelaars FA, Henneman L, Ader HJ et al: Preconceptional cystic fibrosis carrier screening: attitudes and intentions of the target population. Genet Test 2004; 8: 80-89.

20 Poppelaars FA, van der Wal G, Braspenning JC et al: Possibilities and barriers in the implementation of a preconceptional screen- ing programme for cystic fibrosis carriers: a focus group study. Public Health 2003; 117: 396-403.

21 Liamputtong P, Ezzy D: Qualitative Research Methods, 2nd edn. Melbourne: Oxford University Press, 2005.

22 Glaser BG, Strauss AL: The Discovery of Grounded Theory: Strategies for Qualitative Research. Aldine de Gruyter: Chicago, USA, 1967.

23 Baars MJ, Henneman L, ten Kate LP: Preconceptional cystic fibrosis carrier screening: opinions of general practitioners, gynecologists, and pediatricians in the Netherlands. Genet Test 2004; 8: 431-436.

24 Botkin JR, Alemagno S: Carrier screening for cystic fibrosis: a pilot study of the attitudes of pregnant women. Am J Public Health 1992; 82: $723-725$.

25 Morgan MA, Driscoll DA, Mennuti MT, Schulkin J: Practice patterns of obstetrician-gynecologists regarding preconception and prenatal screening for cystic fibrosis. Genet Med 2004; 6: 450-455.

26 Poppelaars FA, Ader HJ, Cornel MC et al: Attitudes of potential providers toward preconceptional cystic fibrosis carrier screening. J Genet Couns 2004; 13: 31-44.

27 Rowley PT, Loader S, Levenkron JC, Phelps CE: Cystic fibrosis carrier screening: knowledge and attitudes of prenatal care providers. Am J Prev Med 1993; 9: 261-266.

28 Watson EK, Mayall ES, Lamb J, Chapple J, Williamson R Psychological and social consequences of a community carrier screening programme for cystic fibrosis. Lancet 1992; 340: 217-220.

29 Loeben GL, Marteau TM, Wilfond BS: Mixed messages: presentation of information in cystic fibrosis-screening pamphlets. Am J Hum Genet 1998; 63: 1181-1189.

30 Marteau TM, Dormandy E, Michie S: A measure of informed choice. Health Expect 2001; 4: 99-108.

31 Mitchell JJ, Capua A, Clow C, Scriver CR: Twenty-year outcome analysis of genetic screening programs for Tay-Sachs and betathalassemia disease carriers in high schools. Am J Hum Genet 1996; 59: 793-798. 